\title{
DOCUMENTOS
}

\section{Necesidad de un proyecto de desarrollo de la música chilena para el siglo XXI}

\author{
por \\ Fernando García Arancibia \\ Academia Chilena de Bellas Artes, Instituto de Chile, Chile
}

Deseo agradecer muy sinceramente el que se me haya otorgado la "Medalla Rector Juvenal Hernández Jaque”, importante galardón que todo universitario quisiera alcanzar algún día. Asimismo, agradezco las afectuosas y benévolas palabras de mi buen amigo Francisco Brugnoli.

Supongo que muchos de los que han recibido la referida distinción se han preguntado, en su momento, la razón de tan honrosa recompensa universitaria. También se habrán cuestionado si lo realizado en favor de la Universidad de Chile merecía tan preciado galardón o si, como miembros de la comunidad universitaria, hicieron lo que debían hacer.

Conociendo la obra amplia y profunda de nuestro ex Rector, obviamente -como a cualquier otro músico- dichas dudas se me presentaron, ya que todos nosotros tenemos conciencia de los trascendentales aportes que hizo el Rector Juvenal Hernández a la actividad musical nacional a través de las instituciones correspondientes de la Universidad de Chile.

El siglo XX llegó a la música chilena después de la Primera Guerra Mundial. Fue en las tertulias de principios de siglo donde los aficionados pudieron escuchar por primera vez obras de Debussy y otros, incluso Schönberg, música que no se programaba en los pocos conciertos que se realizaban. La ópera, especialmente la italiana, era casi la única actividad musical pública que había.

Los compositores jóvenes de entonces emprendieron una campaña para modificar esta situación. En 1917, Domingo Santa Cruz fundó y presidió la Sociedad Bach y en abril de 1924, en una asamblea general, se aprobó lo que hoy conocemos como el proyecto de desarrollo de la música chilena del siglo XX. Igualmente, se acordó transformar la Sociedad Bach en una organización pública, con la finalidad de "fiscalizar" el movimiento musical de Chile y luchar por la formación de las entidades sinfónicas, corales, camarísticas y todo otro organismo que permitiera dar a conocer la música antigua, moderna y de autores

1 Texto del discurso pronunciado con ocasión de la ceremonia de otorgamiento de la Medalla Rector Juvenal Hernández Jaque 2012, realizada en el Aula Magna de la Facultad de Economía y Negocios de la Universidad de Chile el 17 de octubre de 2012. 
nacionales, restando así importancia, en la vida musical local, a la ópera italiana decimonónica. Además, la Sociedad Bach impulsó la reforma del Conservatorio.

El Conservatorio Nacional de Música, dependiente del Ministerio de Educación, fue reformado en 1928, nombrándose como director a un activo miembro de la Sociedad Bach, el violinista, compositor y director de orquesta Armando Carvajal. Este fue el primer paso importante que se dio en la búsqueda de una nueva institucionalidad musical. En los pasos siguientes, el rol de la Universidad de Chile fue crucial.

En diciembre de 1929 el Consejo Universitario acordó la creación de una Facultad de Bellas Artes. Al incluir el arte dentro de las actividades académicas de nuestra Universidad, la institución se identificaba con el pensamiento de Andrés Bello. Desde sus inicios las labores artísticas contaron con un aliado fiel, el Prof. Juvenal Hernández, Rector de la Universidad de Chile entre 1932 y 1953.

No era fácil admitir que en un plantel universitario, cuya principal tarea está íntimamente ligada a las ciencias, convivan éstas con el arte, en particular con la música. Ello es posible sólo si se respetan las características propias del fenómeno musical, entre las cuales resaltan: es ésta una manifestación esencialmente colectiva, ya que para existir plenamente requiere de un creador, un intérprete y un auditor, los tres con misiones distintas; cumple con múltiples funciones en la sociedad; se desenvuelve en el tiempo, por lo tanto, su mensaje se logra descifrar con el transcurrir del discurso sonoro; en la música se mezclan el arte, la ciencia, la tecnología y la artesanía; se comunica a través de un lenguaje de carácter afectivo que, en ocasiones, traspasa lo puramente sonoro, y muchas veces requiere de un aprendizaje temprano. Felizmente este complejo fenómeno fue aceptado por nuestra Universidad.

Desde ese momento, entre otras curiosidades, hubo alumnos "universitarios" de 7 u 8 años de edad, que estudiaban piano, violín, etc. También se creó el Instituto de Estudios Secundarios, donde algunos alumnos de arte de nuestra Universidad podían completar su educación escolar. Como la enseñanza estatal era gratuita, ingresaban al Conservatorio aquellos postulantes que, sin importar la edad, ni condición económica, tenían disposiciones naturales para la música, tenían "talento".

Dentro de la Universidad de Chile desde la década de 1930 se hicieron notables avances en la formación profesional del músico, dándole a la docencia niveles no alcanzados antes. Se crearon las condiciones para el aprendizaje de la musicología y la pedagogía musical; se editaron revistas especializadas; se hizo radiodifusión; se organizaron y apoyaron conciertos en que se interpretaban nuevos repertorios y se ampliaba el público; se subsidió una orquesta sinfónica de 70 músicos, como un primer paso hacia la fundación de una orquesta sinfónica profesional estable; se organizaron concursos de composición, y se editó música chilena.

Si bien la vida musical había dado un salto cualitativo de consideración, particularmente en la formación de intérpretes y compositores, y a poco andar se crearían en la Universidad de Chile las carreras de musicología, para impulsar la investigación musical y pedagogía musical en diferentes especialidades y niveles, aún faltaba por solucionar el problema de la difusión musical, de la formación de público. Esto se comenzó a resolver cuando se dictó la ley No 6696 que creó el Instituto de Extensión Musical (IEM), en octubre de 1940.

Con la reforma universitaria de 1968, las Facultades de Ciencias y Artes Musicales y de Bellas Artes de nuestra Casa de Estudios propusieron -y así se acordó- reconocer la creación 
artística como una función académica universitaria y, también, se agregó como función académica la extensión; vale decir, aquel mecanismo de interrelación con el medio, que es fundamental en la formación de espectadores para la actividad artística y la permanente puesta al día de su enseñanza.

En 1973 la Universidad de Chile se relacionaba con el público de todo el país mediante los organismos del IEM: la Orquesta Sinfónica de Chile, el Ballet Nacional Chileno, el Ballet de Cámara, el Coro Sinfónico, el Coro de Cámara, el Conjunto Folclórico del Coro de la Universidad de Chile, la Ópera Nacional, un cuarteto de cuerdas, un quinteto de vientos y un conjunto de percusiones, así como mediante la presentación de solistas, directores y conjuntos nacionales y extranjeros contratados. Además, por entonces, se había creado la Radio IEM (hoy Radio Universidad de Chile); en tres teatros -uno de ellos era el Teatro IEM- se ofrecían conciertos y funciones de ópera y danza; existía una imprenta donde se publicaba música chilena; se editaban discos de compositores nacionales; se grababan todos los conciertos sinfónicos y de cámara organizados por el IEM, los que se transmitían por distintas radios, desde Arica hasta Punta Arenas, y se seguía publicando la Revista Musical Chilena, fundada en 1945, la que hoy ya cuenta con 67 años de existencia ininterrumpida, siendo la publicación especializada más antigua de habla hispana. Igualmente, existía el concurso Premio por Obra y, a partir de 1948, se realizaban los Festivales Bienales de Música Chilena. Ambos eventos estimularon a los compositores locales a escribir cientos de obras. A lo dicho habría que agregar algunas otras actividades relacionadas con la vida musical, las que, en conjunto con lo anterior, obligan a realizar esfuerzos por recuperar para la Universidad los fondos de la ley $\mathrm{N}^{\circ} 6696$.

Mucho de lo recordado se logró gracias al proyecto de desarrollo de la música chilena para el siglo pasado que propuso la Sociedad Bach y que contó con la comprensión y apoyo de las autoridades de nuestra Universidad, lo que permitió su evolución.

Desgraciadamente, en 1973 la Universidad pasó a ser dirigida por las fuerzas armadas y desapareció el respeto que existía por las especificidades del arte y la música en particular, dañando gravemente el desarrollo alcanzado por ésta en 43 años. El exitoso proyecto de desarrollo de la música para el siglo XX, aplaudido unánimemente (incluso en el extranjero), del cual la Universidad de Chile era un pilar fundamental, fue abruptamente interrumpido y nada lo sustituyó, produciéndose un innegable deterioro de los numerosos planes y tareas que se habían emprendido.

A lo anterior se debe agregar que la gravísima crisis política de 1973 restó, en la defensa de lo realizado, a algunos que habían contribuido decididamente al desarrollo de la música nacional. Ellos olvidaron nuestra propia experiencia, que atestigua que mientras más democracia, mayor ha sido el avance de la música en Chile.

De las iniciativas nacidas antes del golpe militar algunas se han recuperado -la mayoría parcialmente- otras desaparecieron y varias salieron de la Facultad de Ciencias y Artes Musicales y Escénicas o de la Universidad. Es el caso del programa de las orquestas infantiles y juveniles, surgido en la Sede La Serena de la Universidad de Chile, que fue ideado y dirigido por el maestro Jorge Peña Hen, fusilado en 1973. Esta actividad, recuperada por el Ministerio de Educación en 1992, actualmente depende de la Fundación de Orquestas Juveniles e Infantiles de Chile.

La carencia, todavía, de un proyecto que impulse nuestra vida musical nos autoriza a preguntarnos: ¿Los músicos hemos hecho los esfuerzos necesarios para que nuestra 
institucionalidad musical vuelva a tener el nivel y coherencia que tenía en 1973? ¿Hemos trabajado para que dentro de nuestra Universidad nuevamente se asuma de verdad que el complejo mundo de la música -y el arte en general- debe ser tratado como tal en todos sus aspectos, y no como ciencia, tal cual ocurre en el mejor de los casos, o como mercancía, en el caso peor? ¿Cómo podemos devolver a la Universidad de Chile un rol similar al que jugó hasta 1973 en la vida musical del país? ¿Hemos discutido -dentro y fuera de la Universidad- cuál es nuestra situación como músicos en la sociedad actual y qué deseamos para el futuro? Desafortunadamente éstas y otras preguntas similares tienen respuestas que no satisfacen. Por eso, y a pesar de lo recuperado, creo que difícilmente algún músico -yo me incluyo entre ellos- se puede sentir merecedor de la "Medalla Rector Juvenal Hernández Jaque". Todavía falta bastante por recobrar de lo realizado con el apoyo del ex Rector entre 1932 y 1953 en favor de la música y de la Universidad. Aún tenemos una deuda que saldar y mucho que avanzar. Para ello pienso que los músicos debemos reunirnos y analizar nuestro pasado, presente y futuro, y elaborar un proyecto de desarrollo de la música para el siglo XXI, en el cual la Universidad de Chile deberá jugar un papel significativo. 